\title{
ADDICTIVE BEHAVIORS (GAMBLING-INTERNET) IN PATIENTS WITH PSYCHOACTIVE SUBSTANCE USE DISORDER
}

\author{
Tarek Asaad Abdo, Yasser Abdel Razek Mohamed, Mona Ibrahim Awaad, \\ WalaaMohamed Sabry and Abou Mohamed HamedFahmy*
}

\author{
Institute of Psychiatry, The WHO \\ Collaborating Center for Mental \\ Health Research \& Training, and Ain \\ Shams University, Department of \\ Neuropsychiatry, Abbasseyia, Cairo, \\ Egypt. \\ Corresponding author: \\ Abou Mohamed HamedFahmy, \\ Phone: (+2) 01003801826 \\ E-mail: \\ mohammmmad_hamed@yahoo.com \\ Received: 17/9/2020 \\ Accepted: 7/10/2020
}

Online ISSN: 2735-3540

\begin{abstract}
Background: Although a growing body of evidence supported that substance use disorder (SUD) patients are considered a group of population at risk for the development of Addictive Behaviors such as Gambling disorder (GA) and Internet Addiction (IG), only very few studies have been carried out on the Addictive Behaviors among substance use disorder (SUD) patients.
\end{abstract}

Aim of the work: The current study conducted to investigate the prevalence of addictive behaviors in a sample of patients with substance use disorder and comparison in socio-demographic, clinical variables and legal factors in substance dependent individuals with and without addictive behaviors.

Patients and methods: 100 substance use disorder (SUD) patients were included in the study. Full neuropsychiatric history for patients with substance use disorder (SUD) using psychiatric sheet, SCID-I for diagnosis of substance use disorder, Addiction Severity Index (ASI) to assess the severity of substance use disorder, Gambling Addiction Test (GAT) to assess the severity of gambling Addiction and Internet Addiction Test (IAT) to assess the severity of internet addiction.

Results: The prevalence of Addictive Behaviors (Gambling disorder and Internet Addiction) among substance use disorder (SUD) patients was $33 \%$.

Conclusion: These findings demonstrated the high prevalence of Addictive Behaviors among substance use disorder (SUD) patients. Consequently, Addictive Behaviors management should be included in all treatment programs dealing with substance of abuse.

Keywords: Gambling disorder, Internet, prevalence, SUD.

\section{INTRODUCTION:}

Addiction is a primary, chronic disease of brain reward, motivation, memory and related circuitry. Dysfunction in these circuits leads to characteristic biological, psychological, social and spiritual manifestations. This is reflected in an individual pathologically pursuing reward and/or relief by substance use and other behaviors ${ }^{(1)}$.Substance use disorder is one of the most complicated problems that face not only medical professionals but the whole community. This results from the enormous personal, social, and economic costs of such disorder. Moreover, substance use disorder form a cause of preventable illness and death in our country as well as other countries, both developed and developing ones ${ }^{(2,3)}$.

The American Society of Addiction Medicine (ASAM) expanded their definition of addiction to include both behaviors and substances ${ }^{(4)}$. Both behavioral and substance 
addiction have natural histories that may exhibit chronic and relapsing patterns ${ }^{(5)}$.Several converging lines of evidence show an overlap between these conditions and substance dependence in terms of clinical expression (e.g., craving, tolerance, and withdrawal symptoms), comorbidity, neuro-biological profile, heritability, and treatment. Moreover, behavioral and substance addictions share many features in natural history, phenomenology, and adverse consequences. Both forms of addiction typically have onsets in adolescence or young adulthood, with higher rates observed in these age groups than among older adults ${ }^{(6)}$.

Much remains to be understood, however, in the relatively novel field of behavioral addictions. Additionally, wide gaps exist between research advances and their application in practice or public policy settings. This lag is due, in part, to the public perception of behavioral addictions. Whereas drug abuse has well-known and severe negative consequences, those associated with behavioral addictions (e.g., dysfunction within the family unit, incarceration, early school dropouts, financial troubles) are often overlooked despite tremendous implications for public health. Moreover, because engagement in some behaviors with addictive potential is normative and adaptive, individuals who transition to maladaptive patterns of engagement may be considered weak willed and be stigmatized. Thus, research, prevention, and treatment efforts must be furthered and educational efforts enhanced $^{(7,8)}$.

$\boldsymbol{A P A}{ }^{(9)}$ declared that, the prevalence rate of gambling disorder is about $0.2 \%$ $0.3 \%$ in the general population. While the prevalence of Internet gaming disorder is still unclear because of the varying questionnaires, criteria and thresholds employed. The point prevalence in adolescents (ages15-19 years) in one Asian study using a threshold of five criteria was $8.4 \%$ for males and $4.5 \%$ for females. Functional Consequences of Internet Gaming Disorder may tend to crowd out normal social, scholastic, and family activities. Students may show declining grades and eventually failure in school. On the other hand, Functional Consequences of Gambling Disorder may occur from repeatedly lying to others to cover up the extent of gambling or from requesting money that is used for gambling or to pay off gambling debts ${ }^{(10)}$. Internet addiction has been reported to be negatively correlated with academic performance including poor grades, tardiness and procrastinateion ${ }^{(11)}$. Furthermore it has been linked to time and shown to adversely affect sleep habits ${ }^{(12)}$.

\section{PATIENTS AND METHODS:}

\section{Siteofthestudy:}

The study was carried out in the substance abuse treatment department at Abbassia Mental Health Hospital (AMHH). The study was conducted in accordance with the guidelines of the Research and Ethics Committee of the Institute of Psychiatry, Ain Shams University.

\section{Study design:}

It is a Cross sectional, Case- Control observational study.

\section{Subjects:}

According to Med Calc computer program (computer program for medical statistic).100 substance use disorder (SUD) patients was selected from in-patients and out-patients in The Abbassia Mental Health Hospital, addiction treatment unit. The inclusion criteria were Patients to be selected using one or more than substance regularly for at least 1 year who were agreed on sharing in the study, age ranges between 1845 years to exclude mere effect of age and all patients were males. Whereas the 
exclusion criteria represent the Patients with age below 18 or above 45 years.

\section{Procedures}

1) Informed consent: A written consent was obtained from them after explaining the objectives of the study.

2) Full neuropsychiatric history and examination for patients with substance use disorder (SUD)using psychiatric sheet of The Abbassia Mental Health Hospital (AMHH).

3) Arabic version of Structured Clinical Interview for DSM-IV-TR Axis I Disorders (SCID-I): for clinical assessment and diagnosis of substance use disorder and exclude other psychiatric disorders.

4) Addiction Severity Index (ASI): to assess the problems presented by patients with substance use disorder.

5) Gambling Addiction Test (GAT): to assess the severity level of pathological gambling Addiction.

6) Internet Addiction Test (IAT): to assess the severity level of internet and computer addiction.

\section{Measurements:}

\section{1- Structured Clinical Interview for DSM-IV (SCID I) ${ }^{(13)}$.}

The study used the Arabic version of the structured clinical interview for DSM-IV axis I diagnosis (SCID-I) ${ }^{(14)}$. It is a semistructured diagnostic interview which has been updated for DSM-IV.It begins with a section on demographic information and clinical background. Then there are 7 diagnostic modules, focused on different diagnostic groups: mood, psychotic, substance abuse, anxiety, somatoform, eating and adjustment disorders. It is applied to the case group to diagnose drug Dependence and exclude other Axis I diagnosis.

\section{2- Addiction severity Index (ASI $5^{\text {th }} e d$.).}

It is a semi structured interview designed to provide assessment for the problems presented by patients with substance abuse disorder ${ }^{(15)}$. It designed for use in inpatients and outpatients alcohol and drug abuse treatment settings. It gathers information on seven functional areas often affected by substance abuse: medical status, employment and support, drug use, alcohol use, legal status, family or social status and psychiatric status. Each section includes questions about the frequency, duration and severity of the patient's problems over the patient's life and in the last 30 days.The Arabic version of ASI ( $5^{\text {th }}$ ed.) was used ${ }^{(16)}$. Questions include both objective assessment of these problems' severity as well as patient's subjective assessment of them ${ }^{(16,17)}$.

\section{3- Gambling Addiction Test ${ }^{(18)}$ :}

Gambling Addiction Test (GAT) consists of 9 items that measures mild, moderate and severe level of gambling Addiction. Mild: 4-5 criteria met, Moderate: 6-7 criteria met and Severe: 8-9 criteria met.

\section{4- Internet Addiction Test ${ }^{(19)}$ :}

Internet Addiction Test (IAT) is a measure of internet and computer addiction. It consists of 20 items that measures mild, moderate and severe level of pathological Internet Addiction.

\section{5- Statistical methods:}

All data was tabulated, grouped and statistically analyzed using (SPSS 20) (Statistical Package for the Social Sciences) on a compatible PC (personal computer). Data was presented, and suitable analysis was done according to the type of data obtained for each parameter. For descriptive statistics: Mean, Standard deviation ( \pm SD) and range for parametric numerical data. For analytical statistics: Pearson Chi Square Test $\left(\chi^{2}\right)$ : was used to assess the statistical significance of the difference between two study group means, One Way ANOVA Test (F): was used to assess the statistical significance of the difference between more than two study group means, Regression analysis: regression coefficient for 
estimating the relationship between the outcome variables and predictor variables and $\mathbf{P}$ value: Used to indicate the level of significance: $\mathrm{P}>0.05$ : Non significant, $\mathrm{P}<$ 0.05: Significant, $\mathrm{P}<0.01$ : Highly significant and $\mathrm{P}<0.001$ : Very highly significant.

\section{RESULTS:}

\section{- Socio-demographic characteristics:}

Data illustrated in table (1) shows that the mean age of (SUD) patients was 31.5 years $(\mathrm{SD} \pm 6.85), 30.5(\mathrm{SD} \pm 5.12)$ for $(\mathrm{GD})$ patients and $31.09(\mathrm{SD} \pm 6.06)$ for (IA) patients. The whole study sample was unemployed males. As regard the marital status, $(59.09 \%)$ with internet addiction patients, $(63.64 \%)$ with gambling disorder patients and $(59.97 \%)$ of the control were single. As regard the socioeconomic level was: (81.82\%) with internet addiction, $(72.73 \%)$ with gambling disorder and $(86.96 \%)$ of the control were low classes. As regard the education level of the sample was: the internet addiction was $(4.55 \%)$ illiterate education, $(86.36 \%)$ had a precollege education and $(9.09 \%)$ had a college education, the gambling disorder was $(27.27 \%)$ illiterate education, $(63.64 \%)$ had a precollege education and $(9.09 \%)$ had a college education and the control was (7.25\%) illiterate education, $(79.71 \%)$ had a precollege education and $(13.04 \%)$ had a college education.

Table (1): Sociodemographic data of control (SUD), gambling disorder (GD) and internet addiction (IA)

\begin{tabular}{|c|c|c|c|c|c|c|c|}
\hline & & \multicolumn{6}{|c|}{ Groups } \\
\hline & & \multirow{2}{*}{\multicolumn{2}{|c|}{$\frac{(\text { SUD })}{31.5 \pm 6.85}$}} & \multirow{2}{*}{\multicolumn{2}{|c|}{$\begin{array}{c}\text { GD } \\
30.5 \pm 5.12\end{array}$}} & \multirow{2}{*}{\multicolumn{2}{|c|}{$\begin{array}{c}\text { IA } \\
31.09 \pm 6.06\end{array}$}} \\
\hline Age & Mean $\pm \mathrm{SD}$ & & & & & & \\
\hline & & $\mathrm{N}$ & $\%$ & $\mathrm{~N}$ & $\%$ & $\mathrm{~N}$ & $\%$ \\
\hline Gender & Male & 69 & 100.00 & 11 & 100.00 & 22 & 100.00 \\
\hline Occupation & Unemployed & 69 & 100.00 & 11 & 100.00 & 22 & 100.00 \\
\hline \multirow[t]{2}{*}{ Marital status } & single & 40 & 57.97 & 7 & 63.64 & 13 & 59.09 \\
\hline & Married & 29 & 42.03 & 4 & 36.36 & 9 & 40.91 \\
\hline \multirow{2}{*}{$\begin{array}{c}\text { Socioeconomic } \\
\text { level }\end{array}$} & Middle & 9 & 13.04 & 3 & 27.27 & 4 & 18.18 \\
\hline & Low & 60 & 86.96 & 8 & 72.73 & 18 & 81.82 \\
\hline \multirow[t]{3}{*}{ Education } & Illiterate & 5 & 7.25 & 3 & 27.27 & 1 & 4.55 \\
\hline & Precollege & 55 & 79.71 & 7 & 63.64 & 19 & 86.36 \\
\hline & College & 9 & 13.04 & 1 & 9.09 & 2 & 9.09 \\
\hline
\end{tabular}

- The prevalence of Addictive Behaviors (Gambling-Internet) In Patients with Psychoactive Substance Use disorder

Data illustrated in table (2) and figure (1) show that the prevalence of Addictive Behaviors (Gambling 11\% - Internet 22\%) in substance abusers was $33 \%$ and the prevalence of (GD+ IA) was $2 \%$.

Table (2) and Figure (1): Three main groups

\begin{tabular}{|c|c|c|c|}
\hline \multicolumn{3}{|c|}{ Groups } & Three main groups \\
\hline & $\mathrm{N}$ & $\%$ & $\%$ \\
\hline SUD & 69 & 69.0 & 69.0 \\
\hline GD & 9 & 9.0 & $(9+2) 11.0$ \\
\hline IA & 20 & 20.0 & $(20+2) 22.0$ \\
\hline GD+IA & 2 & 2.0 & \\
\hline Total & 100 & 100.0 & 100.0 \\
\hline
\end{tabular}




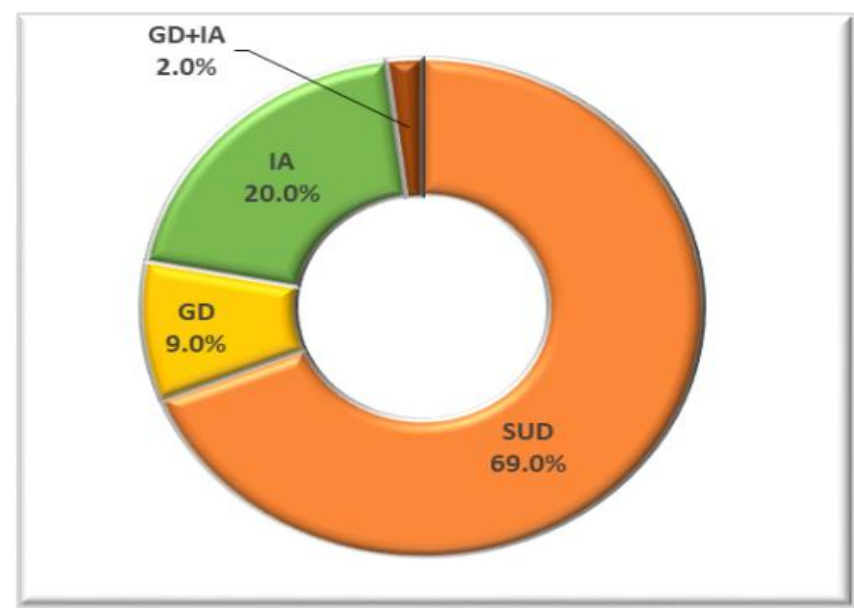

- Comparison between various study groups with regard to legal issue by Addiction Severity Index (ASI):

Data illustrated in table (3) and figure (2) showed a highly statistically significant (HS) difference with P-value was 0.002* (HS).Consequently, Addiction Severity Index (ASI) was found to be a significant scale in assessment of SUD, GD and IA patients. Also, ASI legality sub-cores within Gambling disorder (GD) group was the highest $81.8 \%$ numerically among the study sample followed by (SUD and IA) (31.9\% and $22.7 \%$ ) respectively.

Table (3) and Figure (2): Comparison between various study groups with regard to legal issue by Addiction Severity Index (ASI)

\begin{tabular}{|c|c|c|c|c|c|}
\hline & \multicolumn{3}{|c|}{ Groups } \\
\hline & & & SUD & GD & IA \\
\hline \multirow[t]{4}{*}{ ASI } & \multirow[t]{2}{*}{ no legal } & $\mathrm{N}$ & 47 & 2 & 17 \\
\hline & & $\%$ & $68.1 \%$ & $18.2 \%$ & $77.3 \%$ \\
\hline & \multirow[t]{2}{*}{ legal } & $\mathrm{N}$ & 22 & 9 & 5 \\
\hline & & $\%$ & $31.9 \%$ & $81.8 \%$ & $22.7 \%$ \\
\hline \multirow{2}{*}{\multicolumn{2}{|c|}{ Total }} & $\mathrm{N}$ & 69 & 11 & 22 \\
\hline & & $\%$ & $100.0 \%$ & $100.0 \%$ & $100.0 \%$ \\
\hline \multirow{2}{*}{\multicolumn{2}{|c|}{ Chi-square }} & $\mathrm{X}^{2}$ & \multicolumn{3}{|c|}{12.046} \\
\hline & & P-value & \multicolumn{3}{|c|}{$0.002 *(\mathrm{HS})$} \\
\hline
\end{tabular}

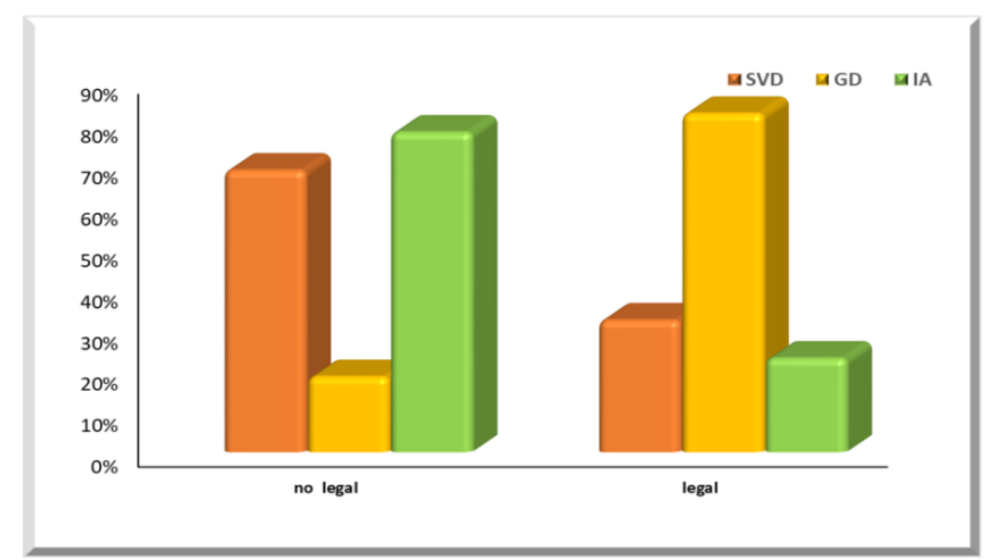

- Association of legal issue by Addiction Severity Index (ASI) among gambling disorder(GD) group related to gambling (GAT) scores .
Data illustrated in table (4) and figure (3)revealed a highly statistically significant (HS) difference with P-value was 0.002*. Also, ASI legal sub-cores within mild $11.8 \%$ 
and severe $14.7 \%$ gambling disorder patients legal subscores $1.5 \%$ and $1.5 \%$ respectively. were higher numerically than those of non-

Table (4) and Figure (3): Association of legal issue by Addiction Severity Index (ASI) among gambling disorder (GD) group related to gambling (GAT) scores

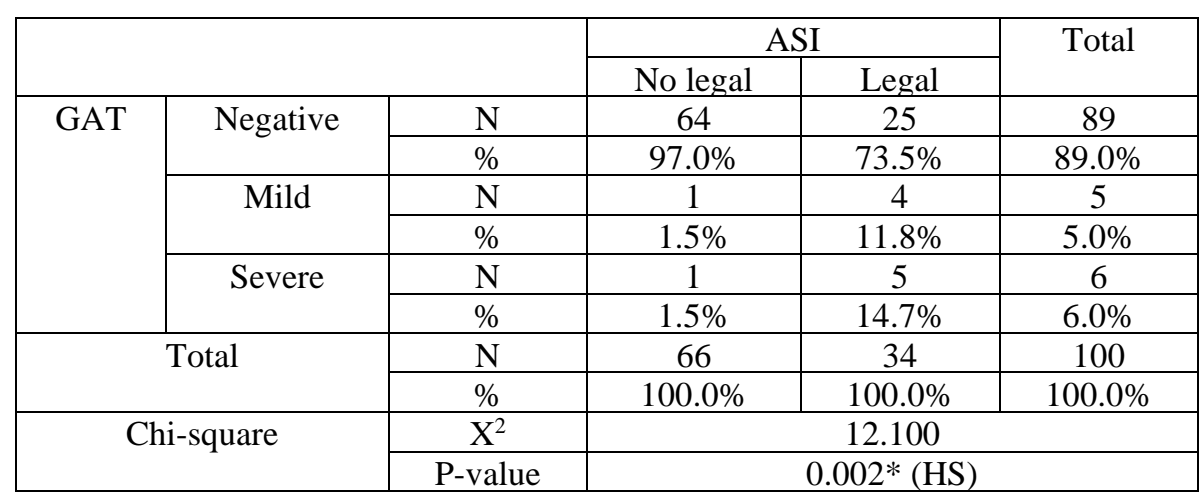

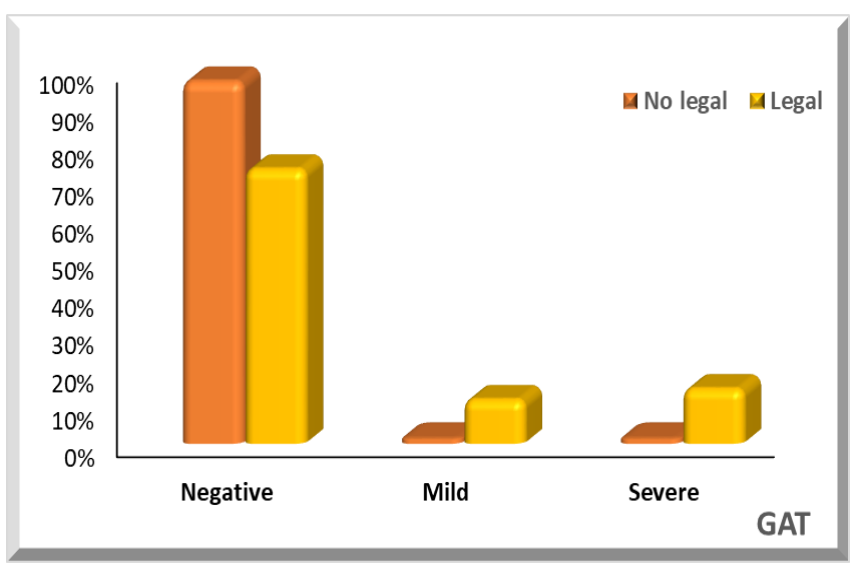

\section{DISCUSSION:}

When studying the socio-demographic of the study sample, our findings revealed that, 100 SUD patients of the sample were recruited and found that, the age range was (18-45) years with mean age 31.5 which are consistent with the studies of Razjouyan et $a l .{ }^{(20)}$ among 223 SUD substance abusers where the mean age of these people was about 35.5 years. Whereas Maarefvand et $a l .{ }^{(21)}$ studied 503 SUD patients and found that the majority of the age of patients $\leq 35$ years was $(61.6 \%)$ while patients $\geq 35$ years was $(38.4 \%)$. These findings may be explained by higher prevalence rate of addiction in young adult groups. In our study, $(100 \%)$ of the sample were males which are consistent with the studies of
Maarefvand et $a l .{ }^{(21)}$ among substance abusers where the all participants were males. In the present study, females could not be included as they do not seek help for fear of the stigma of disorder. In contrast to Razjouyan et al. ${ }^{(20)}$ in their studies where $(96.4 \%)$ were males and $(3.6 \%)$ were females. Also, Baroni et al. ${ }^{(22)}$ in their studies of Problematic Internet use in 183 SUD drug addicts where males to females ratio were (80.87\%):(19.13\%) which could be attributed to different inclusion criteria. However, many studies reported that, there was a high preponderance of men over women in internet addiction ${ }^{(23)}$. As regard the occupation, our study sample was $(100 \%)$ unemployed. these results may be a consequence to functional impairment caused by the disorder in developing 
countries. Whereas, Maarefvand et al. ${ }^{(21)}$ had a different finding as $(64.6 \%)$ of their study cases were employed which may be explained by higher employment rate among the patients in developed countries. When asking about their marital status, the total percentage $(60 \%)$ of the study sample $(40 \%$ SUD, $7 \%$ GD, $13 \%$ IA) were single which is consistent with the study by Baroni et $a l .{ }^{(22)}$ where the total percentage of subjects were $(65.1 \%)$ [ $(50.3 \%)$ single and $(14.8 \%)$ in a love relationship].These findings confirmed the "protective" effects of living together with a partner, as single subjects or those living alone with no family support showed higher risk of internet addiction $^{(24)}$. On the other hand, Razjouyan et $a l .{ }^{(20)}$ in their studies revealed that, (39\%) were single while the majority of the participants $(61 \%)$ were married. Surprisingly, Maarefvand et al. ${ }^{(21)}$ in their studies revealed that, $(18.5 \%)$ were single while the majority of the participants $(81.5$ $\%)$ were married which could be attributed to the large sample size $(n=503)$.

As regard the socioeconomic level of the sample: $(81.82 \%)$ of IA, $(72.73 \%)$ of GD and $(86.96 \%)$ of the controls were low class. Significant low socioeconomic level of the sample may be interpreted as a result of lower education and lower employment rates. As regard the education level, $(9 \%)$ of patients (5\% SUD, 3\% GD, 1\% IA) were illiterate, $(81 \%)$ of patients (55\% SUD, $7 \%$ GD, $19 \%$ IA) had a precollege education and $(12 \%)$ of patients (9\% SUD, 1\% GD, $2 \%$ IA) had a college education which are inconsistent with the findings of the study by Baroni et al. ${ }^{(22)}$ where the total percentage (94.6\%)of a precollege education were 5 years of primary school, completed 8 years of school and the high school $(7.7 \%),(47 \%)$ and $(39.9 \%)$ respectively and $(5.5 \%)$ were graduated college education. On the other hand, Razjouyan et al. ${ }^{(20)}$ in their studies revealed that, $(61.4 \%)$ were a precollege education and (38.6\%) were graduated college education. Also, the study by
Maarefvand et al. ${ }^{(21)}$ revealed that, the total percentage $(100 \%)$ of education level were $0-9$ years $(39 \%)$ and $\geq 10$ years (61\%).These above findings may be explained by higher educational level among patients in developed countries than developing ones as there were no illiterate patients. Our findings showed that age, marital status, socioeconomic level and educational level were not significantly different among control, gambling disorder and internet addiction.

\section{- Prevalence of addictive behaviors among the study sample:}

We found 33 (33\%) out of 100 (SUD) patients had addictive behaviors (11\% Gambling Disorder $+22 \%$ internet addiction). Razjouyan et al. ${ }^{(20)}$; Mozafari et al. ${ }^{(25)}$; Safari ${ }^{(26)}$ in their studies $(\mathrm{n}=223)$ revealed that, the prevalence of IA (mild, moderate, and severe) among participants (SUD) was $(88.4 \%)$. While $(22 \%)$ in our study were IA which could be attributed to the culture of the region, the type of populations studied and the type of abused substances.

Baroni et al. ${ }^{(22)}$ in their studies have found that, almost (10\%) of the individuals (SUD) were suffering from gambling disorder which comes in line with our study $(11 \%)$. Maarefvand et al. ${ }^{(21)}$ in their studies $(n=503)$ revealed that, the prevalence of GD (mild, moderate, and severe) among participants (SUD) was $17.9 \%$ based on Gambling Disorder Screening Questionnaire Persian GDSQ-P and $18 \%$ based on DSM-5 criteria. While $(11 \%)$ in our study were GD which could be due to our small sample size $(n=100)$. Based on DSM-5 (i.e. $\geq 4$ of 9 criteria), 678 individuals $(10.3 \%)$ met a diagnosis of Gambling Disorder ${ }^{(27)}$. Those findings are consistent with our findings in the prevalence of gambling disorder that was found $11(11 \%)$ out of 100 (SUD) patients.

\section{- Clinical characteristics of our study sample:}


In the present study, by applying Internet Addiction Test (IAT), Of the 100 SUD patients, $(22 \%)$ substance use disorder patients with Internet addiction [ $(8 \%)$ for mild, (11\%) for moderate and (3\%) for severe Internet addiction]. While Razjouyan et $\boldsymbol{a l}^{(20)}$ in their studies, (IAT) demonstrated that, Of the 223 SUD patients, about $(88.4 \%)$ substance use disorder patients with Internet addiction [ (55.2\%) for mild, $(25.6 \%)$ for moderate and $(7.6 \%)$ for severe Internet addiction]. Razjouyan et $\boldsymbol{a l}{ }^{(20)}$ studied the prevalence of addiction to the Internet among individuals with a history of drug abuse in Tehran, Iran where there were males and females on methadone and alcohol. In the present study, we could not able to include females as they do not seek help for fear of stigmatization of disorder. The differences in the above mentioned resultscould be attributed tothe culture of the region, the type of populations studied and the type of abused substances.

\section{Association of legal issue by} Addiction Severity Index (ASI) among internet addiction (IA) group related to internet (IAT) scores:

In our study, (ASI) demonstrated that, the whole study sample (100 SUD) was severely ranked, (66\%) patients with no legal issue and (34\%) patients with legal issue. Association of Addiction Severity Index (ASI) among internet addiction (IA) group related to internet (IAT) scores revealed a non-statistically significant (NS) difference. However, ASI legal sub-core $5.9 \%$ was higher than that of non-legal subcore $1.5 \%$ in severe internet addiction patients.

Association of legal issue by Addiction Severity Index (ASI) with the type of abused substance:

In our study, the type of abused substance revealed that, the highest intake was $79 \%$ Heroin use disorder which comes in line withRazjouyan et al. (20)in their studies that revealed the highest intake was
77.6\% Heroin use disorder. While, Baroni et $\boldsymbol{a l} .{ }^{(22)}$ in their studies revealed that, the highest intake was $48.1 \%$ Heroin use disorder. In our study, Association of Addiction Severity with the type of abused substance revealed that, there was statistically significant association with heroin intake while other substances don't. Also, ASI legal sub-core91.2\% was higher than that of non-legal subscore $72.7 \%$ in Heroin use disorder.

In the present study, by applying Gambling Addiction Test (GAT), Of the 100 SUD patients, (11\%) substance use disorder patients with Gambling Disorder [ $(5 \%)$ for mild, (0\%) for moderate and $(6 \%)$ for severe Gambling Disorder].While Maarefvand et al. ${ }^{(21)}$ in their studies, (GAT) demonstrated that, Of the 503 SUD patients, (18\%) substance use disorder patients with Gambling Disorder [(7.6\%) for mild, $(6.8 \%)$ for moderate and (3.6\%) for severe Gambling Disorder].

Association of legal issue by Addiction Severity Index (ASI) among gambling disorder (GD) group related to gambling (GAT) scores:

In the present study, Association of Addiction Severity Index (ASI) among gambling disorder (GD) group related to gambling (GAT) scores revealed a highly statistically significant (HS) difference. Also, ASI legal sub-cores within mild $11.8 \%$ and severe $14.7 \%$ gambling disorder patients were higher than those of non-legal subscores $1.5 \%$ and $1.5 \%$ respectively. However, the "Illegal Acts" (legal issue) criterion was omitted from DSM-5 diagnosis ${ }^{(27,28,29)}$.

Comparison between various study groups with regard to the type of abused substance:

In the present study, comparison between various study groups with regard to the type of abused substance revealed that, a non-statistically significant (NS) association. However, gambling disorder (GD) group was the highest among study groups 
regarding Heroin intake with P-value: $0.055^{*}$ that found to be the nearest for statistically significance.

Association between various study groups with regard to legal issue by Addiction Severity Index (ASI):

In our study, association between various study groups with regards to severity of addiction revealed that, a highly statistically significant (HS) difference. Consequently, Addiction Severity Index (ASI) was found to be a significant scale in assessment of SUD, GD and IA patients. Also, ASI legality sub-cores within Gambling disorder (GD) group was the highest $81.8 \%$ among the study sample followed by (SUD and IA) $(31.9 \%$ and $22.7 \%$ ) respectively.

\section{Role of funding source:}

The authors of this manuscript declare that no funding bodies were involved in sponsoring or funding this research.

\section{Conflicts of interest:}

Disclosure of conflict of interest: All authors declare no actual or potential conflict of interest whether financial, personal or otherwise related to this manuscript.

\section{REFERENCES:}

1. American Society of Addiction Medicine (ASAM) Public Policy Statement (2015): Definition of Addiction: Available online: http://www. asam. Org/for-the-public/ definition-of-addiction.

2. Haroon A (2000): Basic Principles of Substance Use Disorders: Introduction. In Haroon A (eds.) Cairo 1-4.

3. Elhabiby M, Ghanem M, Asaad T, Mansour M, Soliman MA, Mohamed A (2009): Sleep Profile in patients with chronic opiate abuse. M.D. degree thesis in Psychiatry, Ain Shams University-Faculty of Medicine.
4. Love T, Laier C, Brand M, Hatch L, Hajela R (2016): Neuroscience of Internet Pornography Addiction: A Review and Update. Doan A, ed. Behavioral sciences, 5(3), 388-433. PMC, Web. http://doi. org/10.3390/bs5030388.

5. Slutske WS (2006): Natural recovery and treatment-seeking in pathological gambling: results of two U.S. national surveys. Am J Psychiatry, 163(2):297-302.

6. Leeman RF, Potenza MN (2013): A targeted review of the neurobiology and genetics of behavioral addictions: an emerging area of research. Can $J$ Psychiatry. 58:260-73.

7. Wang J, Xiao JJ (2009): Buying behavior, social support and credit card indebtedness of college students. Int J Consum Stud. $33: 2-10$.

8. Lejoyeux M, Weinstein A (2010): Compulsive buying. Am J Drug Alcohol Abuse, 36:248-53.

9. American Psychiatric Association (APA) (2013): Section II- Diagnostic Criteria and Codes, Substance-Related and Addictive Disorders, Gambling Disorder. Diagnostic and Statistical Manual of Mental Disorders 5th ed. American Psychiatric Publishing; Arlington, VA, USA, 585-589.

10. O'Brien PC, Crowley JT (2013): DSM-5 Work Groups, Substance Related and Addictive Disorders, Gambling Disorder. American Psychiatric Association (APA). Diagnostic and Statistical Manual of Mental Disorders 5th ed. American Psychiatric Publishing; Arlington, VA, USA, 585-589.

11. Chang MK, Law SPM (2008): Factor structure for Young's Internet Addiction Test: A confirmatory study. Computers in Human Behavior, 24, 2597-2619.

12. Kesici S, Sahin I (2010): Turkish adaptation study of Internet Addiction Scale. Cyberpsychology, Behavior, and Social Networking, 13(2), 185-189.

13. First M, Spitzer R, Gibbon M, et al. (1997): Structured Clinical Interview for DSM-IV 
Axis I disorders (SCID I). New York: Biometric Research Department.

14. Missiry A, Sorour A, Sadek A, et al. (2004): Homicide and Psychiatric Illness: An Egyptian Study. M.D. thesis. Faculty of Medicine. Ain Shams University.

15. McLellan AT, Kushner H, MetzgerD, Peters R, Smith I, Grisson G, Pettinati H and Argeriou M (1992): The fifth edition of Addiction severity index. Journal of Substance Abuse Treatment 9, 199-213.

16. Qassem T, Beshry Z, Asaad T, Omar A, Abdel Mawgoud M (2003): Profiles of Neuropsychological Dysfunction in Chronic Heroine Users. M.D. degree thesis, Faculty of Medicine, Ain Shams University.

17. Khalil A, Okasha T, Shawky M, Haroon A, Elhabiby M, Carise D, Jeffrey AJ, Hasson AM, Rawson RA (2008): Characterization of Substance Abuse Patients Presenting for Treatment at a University Psychiatric Hospital in Cairo, Egypt. Addictive Disorders \& Their Treatment. 7(4):199-209.

18. Segal J, Smith M,Robinson L (2016): Gambling Addiction and Problem Gambling: Warning Signs and How to Get Help for YourGamblingProblem.www.helpguide.org

19. Young KS (2009): Internet Addiction: The Emergence of a New Clinical Disorder. Cyber Psychology \& Behavior, 1(3): 237244. doi:10.1089/cpb.1998.1.237.

20. Razjouyan K, Hamzenejhad P, Khademi M, Arabgol F (2018): Data on the prevalence of addiction to the Internet among individuals with a history of drug abuse. www.elsevier.com/locate/dib.https://doi.org /10.1016/j.dib.2018.09.052;1216-1219.

21. Maarefvand M, Mardaneh-Jobehdar M, Ghiabi M, Rafimanesh H, Mohammadi A, Morshedi Z, et al. (2019): Designing and Evaluating the Validity and Reliability of the Persian Gambling Disorder Screening Questionnaire. Addict Health; 11(2): 110119.

22. Baroni S, Marazziti D, Mucci F, Diadema E, Dell'Osso L (2019): Problematic Internet use in drug addicts under treatment in public rehab centers. World $J$ Psychiatr; 9(3): 55-64.

23. Istituto Superiore di Sanità (2017): Indaginesullecaratteristiche esull'operativitàdeiservizie dellestrutture per iltrattamento del disturbo da gioco di azzardo; http: // old. iss. it / binary / ogap / cont / Indagine_sulle_caratteristiche_e_sull_oper ativita_768_.pdf 40

24. McCreary AC, Müller CP, Filip M. (2015): Psychostimulants: Basic and Clinical Pharmacology. Int Rev Neurobiol; 120: 41 83.

25. Mozafari M, SafariY, Abasifard Z, Safari M, Sharafi K (2016): Assessing dimension of metacognitive skills and its relationship with academic achievement in high school students. Acta Med. Mediterr. 32;899-903.

26. Safari Y (2015): Clarifying evidence-based medicine in educational and therapeutic experiences of clinical faculty members. $a$ qualitative study in Iran,Glob.J.HealthSci.7; 62-68.

27. Rennert L, Denis C, Peer K, Lynch KG, Gelernter J, Kranzler HR (2015): DSM-5 Gambling Disorder: Prevalence and Characteristics in a Substance Use Disorder Sample. Exp Clin Psychopharmacol; 22(1): 50-56. doi:10.1037/a0034518.

28. Petry NM, Blanco C, Stinchfield R, Volberg R. (2013): An empirical evaluation of proposed changes for gambling diagnosis in the DSM-5. Addiction.108:575-581.

29. Strong DR, Kahler CW (2007): Evaluation of the continuum of gambling problems using the DSM-IV. Addiction.102:713-721. 


\section{السلوكيات الإدمانية(القمار- الإنترنت)}

في مرضى سوء استخدام الموادذاتالتأثير النفسى الأنئن

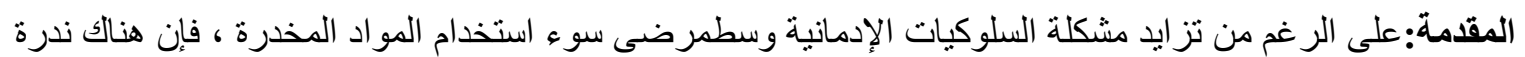

شديدة في الأبحاث التي تناولت هذا الموضوع وذللك على مستوى العالموبناء على ذللك ظهرت أهمية إجر اء هذه الدر اسة.

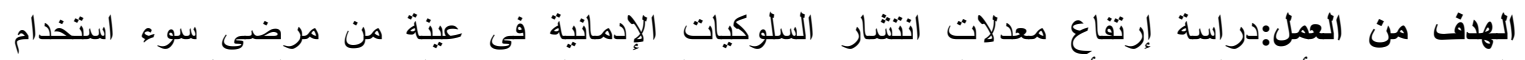

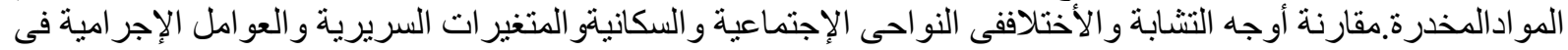
مرضى سوء استخدام المو اد المخدرة مع أو بدون السلوكيات الإدمانية.

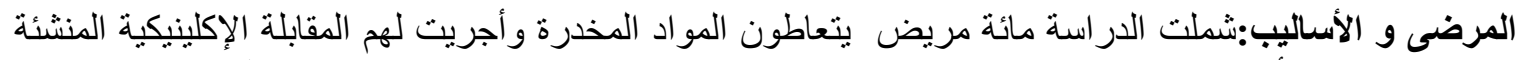
للتشخيص الإحصائي الأمريكي SCID-1 ومقياس شدة الإدمان ومقياس إدمان الإنترنت ومقياس إدمان القمار.

النتائج:معدل انتشار السلوكيات الإدمانية (القمار 22\%و الإنترنت 11\%) فى مرضى سوء استخدام المواد المخدرة

الخاتمة: توصلت هذه الدراسة إلى إرتفاع معدلات انتشار السلوكيات الإدمانية فى مرضى سوء الإنى إتخدام المواد

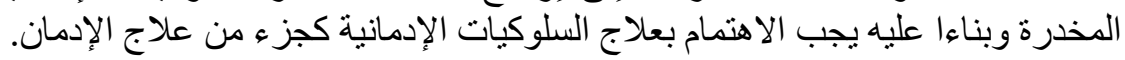

